\title{
PROCESSO DE VOÇOROCAMENTO E FEIÇÕES SECUNDÁRIAS: UM ESTUDO DE CASO EM MANAUS-AM
}

\author{
Armando Brito da Frota Filho \\ Doutorado em Geografia \\ Universidade Federal do Rio de Janeiro - UFRJ \\ armando geomorfo@outlook.com \\ Nádia Rafaela Pereira de Abreu \\ Mestre em Geografia \\ Universidade Federal do Amazonas - UFAM \\ nadiarafaela1@hotmail.com \\ Antonio Fábio Sabbá Guimarães Vieira \\ Prof. Dr. Departamento de Geografia \\ Universidade Federal do Amazonas - UFAM \\ fabiovieira@ufam.edu.br
}

\section{RESUMO}

As voçorocas são incisões erosivas que surgem por ações naturais e humanas, modificando a paisagem. Assim, para este trabalho, foi escolhida a voçoroca localizada no bairro Nova Cidade para maior detalhamento. Nesta, foi realizada a caracterização dos parâmetros morfométricos (tipo, forma e tamanho), e das feições de retrabalhamento, assim como a identificação dos seus impactos. Para isso, foram utilizados parâmetros já consagrados para classificar a voçoroca quanto ao "tipo", "forma", "tamanho" em trabalhos de campo. Em síntese, a incisão em questão é do tipo conectada, apresenta forma irregular e teve volume erodido de 119.981,52 $\mathrm{m}^{3}$, apresentando como principais feições secundárias no seu interior, marmitas e alcovas de regressão. Dentre os diversos impactos causados pela voçoroca está a perda de solo e assoreamento do canal à jusante.

Palavras-chave: Voçoroca. Feições de retrabalhamento. Impactos ambientais.

\section{GULLY PROCESS AND SECONDARY FEATURES: A CASE STUDY IN MANAUS-AM}

\begin{abstract}
Gullies are erosive incisions that arise through natural and human actions, modifying the landscape. Thus, for this work, the gully located in the Nova Cidade district was chosen for further details. In this, the characterization of the morphometric parameters (type, shape and size), and the rework features were carried out, as well as the identification of their environmental impacts. For this purpose, it was established parameters were used to classify the gully in terms of "type", "shape", "size" carried out in field work. In summary, the incision in question is of the connected type, has an irregular shape and had an eroded volume of $119,981.52 \mathrm{~m}^{3}$, presenting as main reworking features inside, the kettles and regression alcoves. Among the various impacts caused by the gully is the loss of soil and silting of the channel downstream.
\end{abstract}

Keywords: Gullies. Remodeling features. Environmental impacts.

\section{INTRODUÇÃO}

Ao se considerar o modelado do relevo como um sistema resultante das interações de fatores físicos, químicos, biológicos e sociais que se relacionam no espaço e no tempo, qualquer alteração, em um desses componentes do ecossistema pode alterar o sistema, causando desequilíbrios. Isso fica mais evidente quando ocorre a interferência do fator antrópico sobre a natureza.

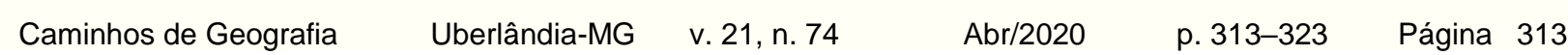


Os níveis de interferências antrópicas variam no espaço, e influenciam em menor ou maior escala os processos erosivos, devido às alterações no escoamento superficial, promovidas pelas condições do solo, ocorrendo a redução da infiltração e ampliação da ocorrência de escoamento superficial (TUCCI; CLARKE, 1997; WOO et al.,1997; BOTELHO, 2011).

Em ambientes urbanizados essas intervenções antrópicas e os processos erosivos são mais nítidos, como atestam Rodrigues; Moroz-Caccia Gouveia (2013). O processo de urbanização pode provocar diversos distúrbios, dentre os quais se destacam o desenvolvimento de incisões erosivas lineares, como as voçorocas, as quais são conhecidas por representarem significativas perdas do solo. Em sítios urbanos, tais incisões apresentam um grave problema, pois diminuem a área a ser ocupada e ampliam as possíveis áreas de risco, face à proximidade com as habitações.

$\mathrm{Na}$ cidade de Manaus, as voçorocas são resultantes de uma combinação da topografia, com destaque para a declividade, e o alto índice pluviométrico, captado por um sistema de drenagem pluvial deficiente que resultou até o ano de 2008, na ocorrência de 91 voçorocas (VIEIRA, 2008).

Em 2012 esse número foi reduzido para 46 voçorocas em toda a cidade (ABREU et al., 2012; FROTA FILHO et al., 2012). Tal resultado decorreu de dois fatores: à interferência do poder público na contenção das incisões (direta ou indiretamente), e a união de voçorocas muito próximas umas das outras, formando uma única incisão. No caso das contenções diretas, trata-se simplesmente de obras direcionadas para esse fim, ao passo que as obras indiretas, referem-se à obras de drenagem urbana, por exemplo, em que no caminho destas existia uma voçoroca. Assim, a obra não havia sido direcionada à esta incisão em particular, mas sim para outra necessidade e que por conta dessa, acabou sendo beneficiada pela obra principal, com a consequente contenção.

Considerando o número de voçorocas em Manaus, o presente trabalho teve como objetivo a descrição mais detalhada de uma voçoroca, localizada no bairro Nova Cidade, na Zona Leste de Manaus (0259'34.73S e 5958'38.66”W). Tal feição, foi escolhida por estar ativa e apresentar várias feições de retrabalhamento e também pelos impactos causados. Desta forma, os objetivos propostos foram o de identificar os parâmetros morfométricos da voçoroca, caracterizar a evolução da expansão desta e descrever as feições de retrabalhamento e os impactos decorrentes.

\section{METODOLOGIA}

\section{Área de estudo}

A cidade de Manaus está inserida na Formação Geológica Alter do Chão que tem constituição iniciada no Albiano Médio a Superior (entre 112 a 99,6 Ma - na Era Mesozóica, Período Cretáceo Inferior), estendendo-se pelo Cenominiano (99,6 a 93,5 Ma - Cretáceo Superior) ao Turoniano (93,5 a 89,3 Ma - Cretáceo Superior), conforme descrito por Leal (1996), cujos arenitos apresentam granulação fina a grossa, de coloração variante de branca, rósea, vermelha a cinza-claro, com grãos subarredondados e arredondados, às vezes conglomeráticos e concreções lateríticas devido a presença de ferro (COSTA et al., 1978).

Sobre esta se desenvolve a Unidade Morfoestrutural do Planalto Dissecado do Rio Trombetas/Rio Negro representado por um sistema de colinas tabuliformes pequenas e médias (SILVA, 2005), com altimetria atingindo cotas de até 119 metros (VIEIRA, 2008). Com vales fechados, estreitos e encaixados e zonas de interflúvios estreitas e alongadas, rodeados por uma intricada e densa rede drenagem, com orientações preferenciais de NW-SE e NE-SW (AB'SABER, 1953, SILVA, 2005).

Os solos de Manaus apresentam algumas classes dominantes, como os Latossolos Amarelos, localizados nos platôs e nas encostas, os Argissolos, preferencialmente nas vertentes e os Espodossolos, encontrados normalmente nas porções inferiores da encosta e/ou nos fundos de vale (FIGURA 1), confirme Lucas (1989) e Vieira (2008). 
Figura 1 - Representação esquemática dos solos nas vertentes da região norte da cidade de Manaus.

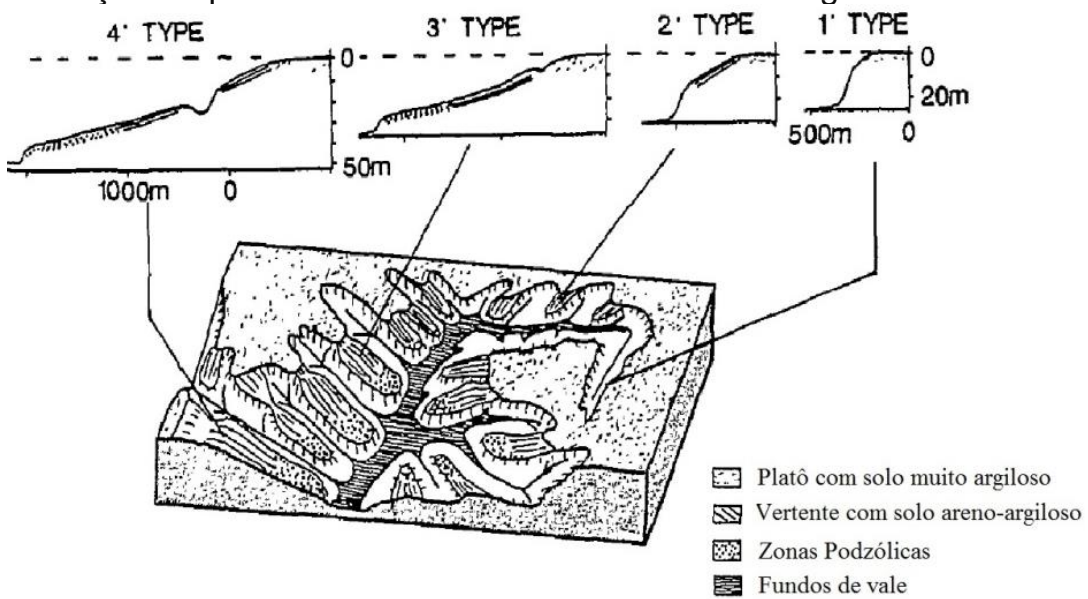

Fonte - Lucas, 1989.

A vegetação predominante é constituída pelas espécies que compõem a Floresta Ombrófila Densa e o clima que a sustenta é caracterizado por apresentar uma estação seca de curta duração, o que se enquadra na classificação de Köppen, como Clima A (Clima Tropical Chuvoso) ou mais especificamente Amw. Esse tipo climático para Manaus, apresenta um valor médio de pluviosidade acumulada de $2.291,8 \mathrm{~mm}$ em (D'ÀVILA JUNIOR, 2016). A temperatura média é $26^{\circ} \mathrm{C}$, com máximas de $32^{\circ} \mathrm{C}$ e mínimas de $23^{\circ} \mathrm{C}$ (AGUIAR, 1995).

A voçoroca estudada se localiza na Latitude 0259'34.73" S e Longitude 5958'38.66” W (FIGURA 2), no bairro Nova Cidade, zona leste da cidade de Manaus -AM.

Houve um processo de remoção da vegetação, com posterior terraplanagem, que resultou na perda dos horizontes $\mathrm{O}$, A e parte do Horizonte B do Latossolo Amarelo. Soma-se a isso a compactação do solo e a declividade natural do terreno com posterior voçorocamento.

Figura 2 - Voçoroca no bairro Nova Cidade, Manaus-AM.

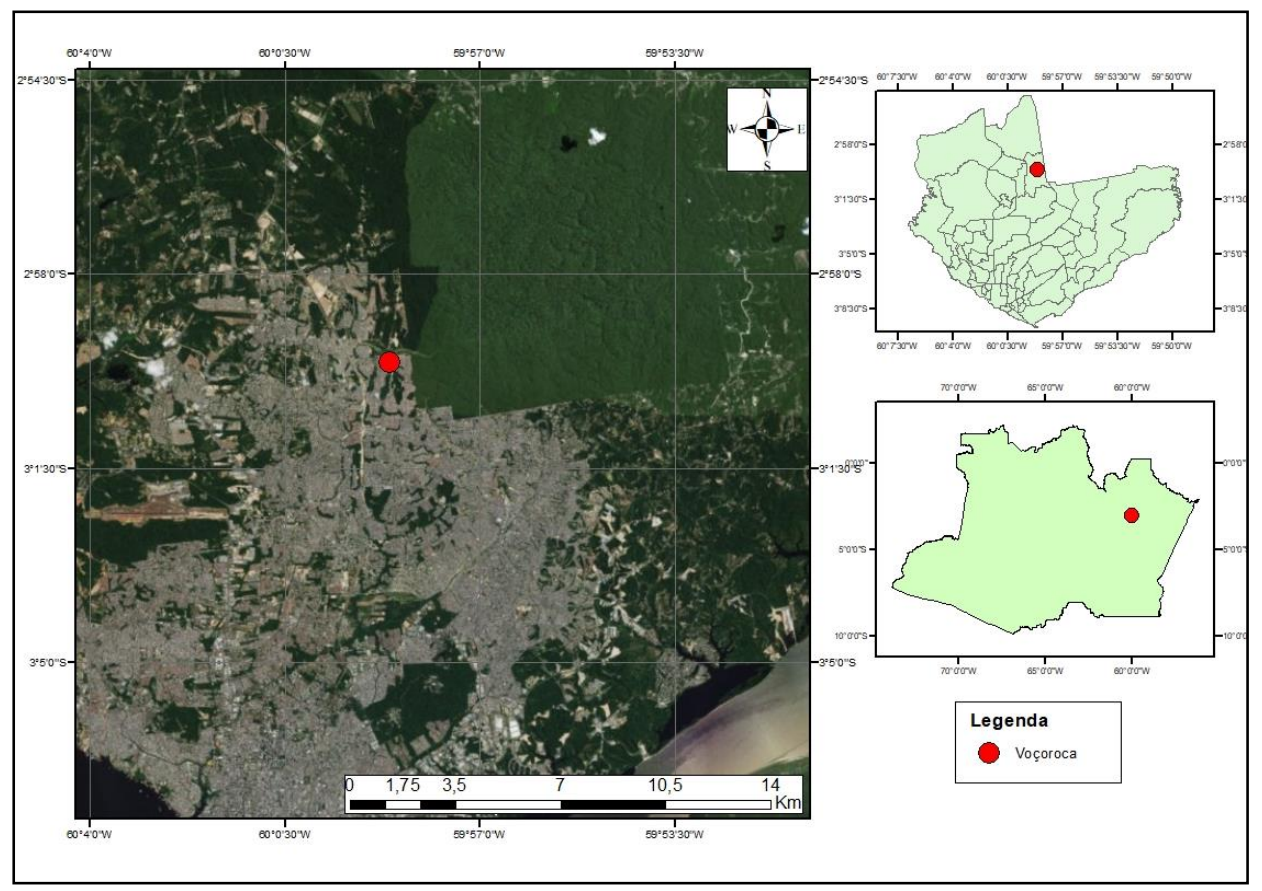

Fonte - Google Earth (2014)

Org.: Armando Brito da Frota Filho, 2020. 


\section{Identificação dos parâmetros morfométricos da voçoroca}

Para identificação da morfometria da voçoroca foi utilizada imagens obtidas pelo software Google Earth versão 4.2 de abril de 2014, e por meio do software QuantumGIS 10.1 foi delimitada seu polígono, sendo obtidos o perímetro e área da incisão. In loco, foram aferidas as profundidades em 4 segmentos, sendo realizadas na incisão, sendo uma medição na cabeceira, duas no meio e uma à jusante, obtendo-se a profundidade média. Com base na área aferidos em ambiente de SIG e a média da profundidade obteve-se o volume erodido aproximado.

A identificar do tipo e forma, conforme os modelos propostos por Oliveira (1989), na figura 3A, e de Vieira (2008), na figura 3B, assim como o tamanho da incisão pelo modelo de Albuquerque;Vieira (2004), no quadro 01.

Figura 3 - a) Tipos de voçorocas.

A
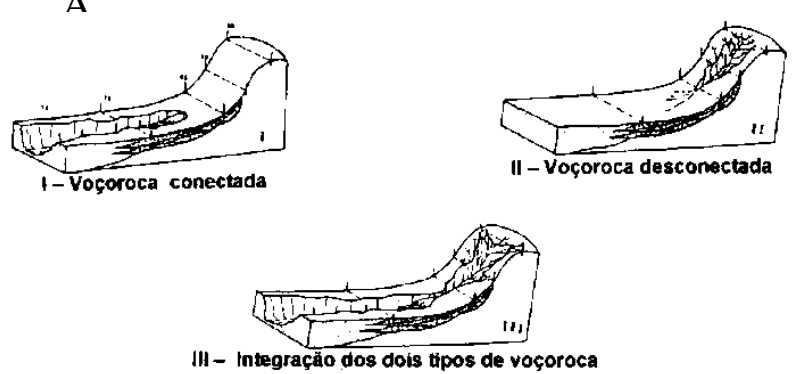

III - Integraçăo dos dois tipos de voçoroca

Fonte - Oliveira (1989).
Figura 3 - b) Formas de voçorocas.

B

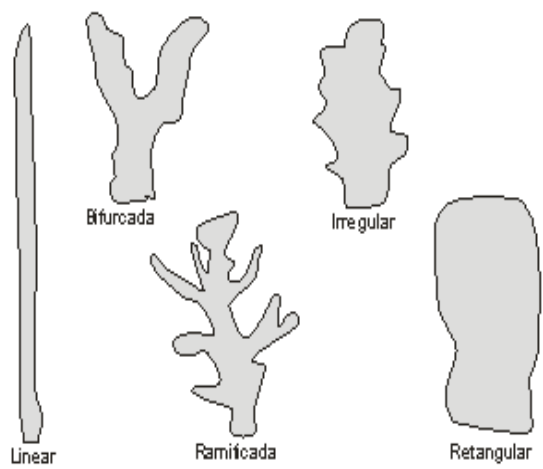

Fonte - Vieira (2008).

Quadro 01 - Classificação das voçorocas por tamanho $\left(\mathrm{m}^{3}\right)$.

\begin{tabular}{|l|c|c|}
\hline Ord. & $\begin{array}{c}\text { Volume erodido } \\
\left(\mathbf{m}^{\mathbf{3}}\right)\end{array}$ & Tamanho \\
\hline $\mathbf{0 1}$ & Até 999 & Muito pequena \\
\hline $\mathbf{0 2}$ & De 1.000 até 9.999 & Pequena \\
\hline $\mathbf{0 3}$ & Entre 10.000 e 19.999 & Média \\
\hline $\mathbf{0 4}$ & Entre 20.000 e 40.000 & Grande \\
\hline $\mathbf{0 5}$ & Mais de 40.000 & Muito grande \\
\hline \multicolumn{2}{|c|}{} \\
Fonte - Vieira; Albuquerque (2004).
\end{tabular}

\section{Caracterização da direção do crescimento, feições de retrabalhamento e os impactos dos sedimentos da voçoroca.}

Foi utilizada a ferreamente série histórica do Google Earth, referente aos anos de 2005 e 2014, para caracterizar a direção do crescimento da voçoroca. Em campo foram identificadas quais as feições de retrabalhamento (marmitas e alcovas de regressão) ocorrem no interior e nas bordas da voçoroca. Baseando-se em estudos de Vieira (2008) e Guerra; Guerra (2010), a presença dessas feições também indicam a direção de crescimento da voçoroca.

\section{RESULTADOS E DISCUSSÃO}

\section{Identificação dos parâmetros morfométricos da voçoroca}

Houve a retirada da vegetação originária da área além do processo de terraplanagem que removeu os horizontes $\mathrm{O}$ e $\mathrm{A}$ completamente e parcialmente o horizonte B. Essa camada remanescente foi compactada, dificultou a infiltração das águas da chuva, favorecendo assim, o escoamento

\begin{tabular}{llllll}
\hline Caminhos de Geografia & Uberlândia-MG & v. 21, n. 74 & Abr/2020 & p. 313-323 & Página 316
\end{tabular}


superficial. À medida que o escoamento se tornou concentrado, sulcos surgiram em vários pontos dessa área que se expandiram dando origem a voçoroca, objeto de estudo do presente trabalho.

Em trabalhos de campo anteriores e por meio da análise da série histórica de imagens de satélite (Google Earth), referente ao ano de 2005, essa voçoroca possuía uma forma linear. Com o passar do tempo o processo de compactação do solo favoreceu o escoamento superficial com fluxos superficiais concentrados, que convergiam para a borda da incisão, modificando-a para a forma irregular, em 2014. Esta incisão foi classificada quanto ao tipo em conectada, pois se encontra ligada ao canal existente na área.

Para se mensurar o volume erodido foi delimitado um polígono no QuantumGIS, do qual foi possível determinar a área aproximada de $17.579,71 \mathrm{~m}^{2}$, em seguida esse valor foi multiplicado pela média das quatro profundidades verificadas na voçoroca $(6,82 \mathrm{~m})$ (FIGURA 4), chegando-se ao valor de $119.981,52 \mathrm{~m}^{3}$ de material erodido da voçoroca, caracterizando-a como uma voçoroca de tamanho muito grande. Essa feição encontra-se ativa e tende a aumentar de tamanho. A ausência de vegetação na área do entorno da incisão e a grande quantidade de processos de retrabalhamento no interior desta, corroboram para esse aumento.

Figura 4 - Voçoroca tipo Conectada, forma Irregular e de tamanho Muito Grande. Bairro Nova Cidade, Manaus-AM.

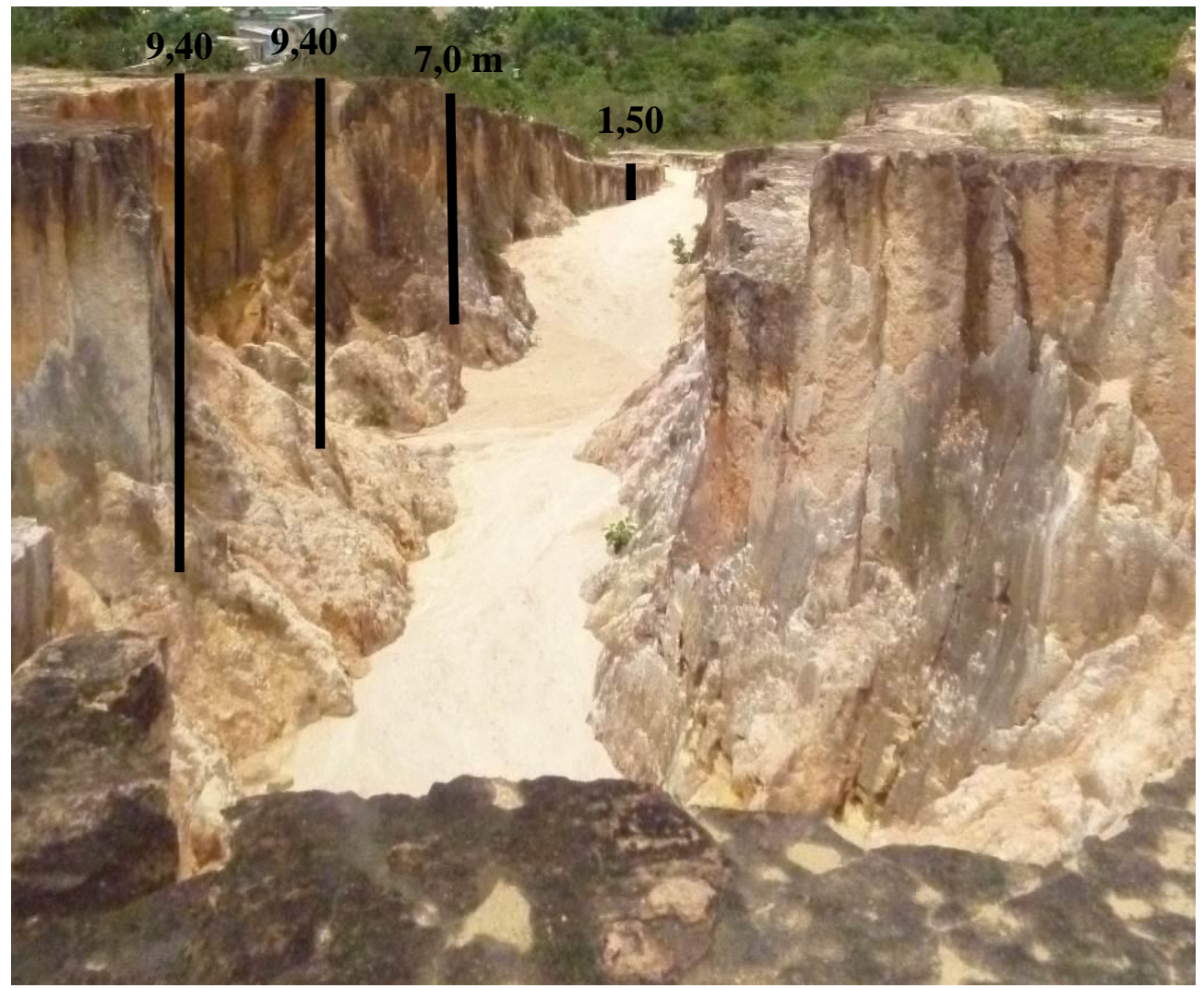

Fonte - Armando Brito da Frota Filho, 2017.

\section{Caracterização das feições de retrabalhamento e impactos correlativos à voçoroca.}

A voçoroca apresenta feições de retrabalhamento como alcovas de regressão e marmitas (torrenciais e residuais), assim como cicatrizes de movimentos de massa, que são indicadores que a incisão se encontra ativa além de área de deposição na porção à jusante da incisão (FIGURA 5).

$\mathrm{Na}$ figura 5 estão localizados os pontos referentes as feições de retrabalhamento como marmitas residuais, movimentos de massa e alcovas de regressão, além da área de deposição a jusante da voçoroca. 
Figura 5 - A. Marmitas residuais em solo compactado; B. Movimentos de massa; C. Alcovas de regressão; D. Área de deposição.

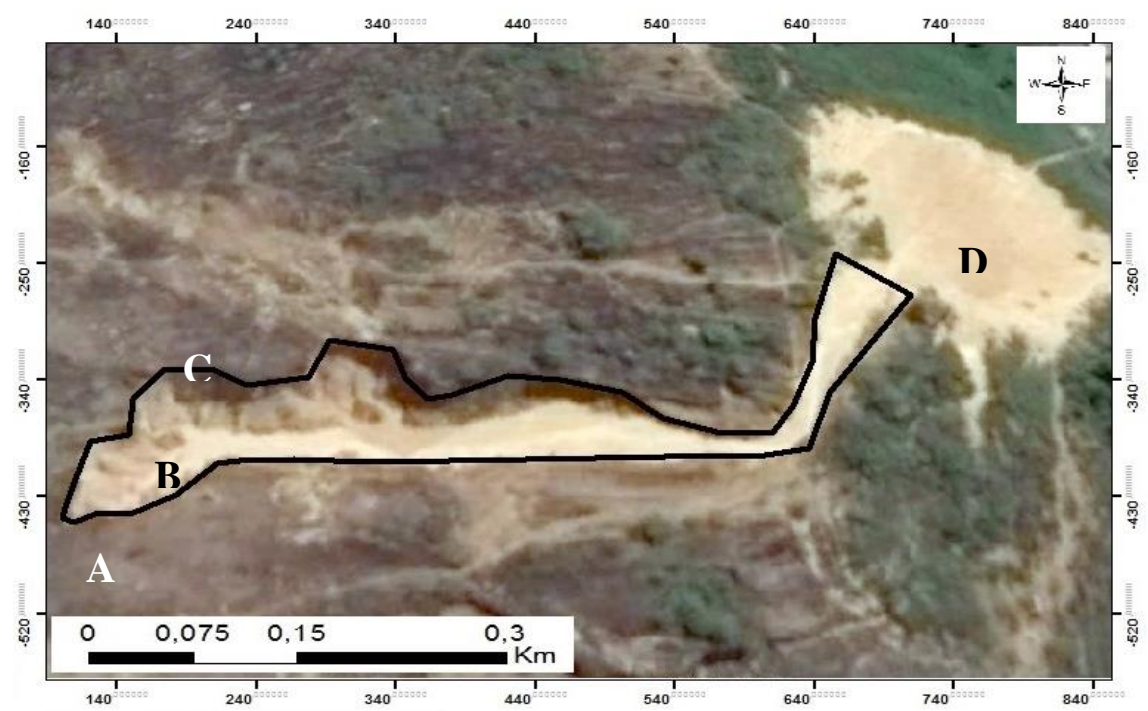

Fonte - Google Earth, 2014. Org: Armando Brito da Frota Filho, 2020.

As feições de retrabalhamento encontradas no interior da voçoroca estão mais presentes nas reentrẩncias de sua cabeceira. A ação exercida por essas feições configura-se como um processo contínuo de expansão e modificação da voçoroca.

As marmitas demonstram o papel de desgaste da superfície do solo compactado, com alargamento e aprofundamento dos sulcos e ravinas que levam água da chuva para o interior da voçoroca. Assim, nesse processo, ficam as marcas de suas ações na parede da incisão, daí o nome de "marmitas residuais" (FIGURA 6 A e B).

Figura 6 - A. Marmitas residuais em solos compactado. B. Marmitas Residuais.

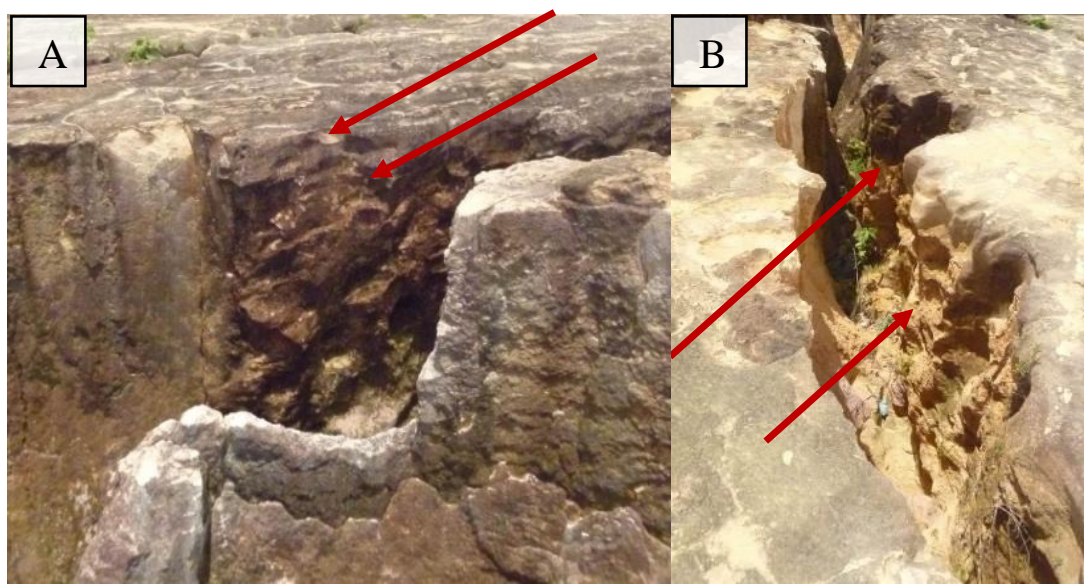

Fonte - Google Earth, 2014.Org: Armando Brito da Frota Filho. 2017.

Essa movimentação das camadas de solo acima da alcova, segundo Selby (1990), está relacionada à força gravitacional, é influência da água. A forma arredondada da cicatriz (Figura 7) indica que ela pode ser o resultado de um escorregamento rotacional, ocorrido naturalmente, onde a base da parede da voçoroca foi solapada pela força da água (SELBY, 1990). As camadas de solos removidas são depositadas no fundo da voçoroca e parte desses sedimentos são carreados para a rede drenagem, e a outra parte que não são carreados pela força da água ou do vento, ficam retidos no fundo da voçoroca e são aplainados, dando a característica de fundo plano e formato em U (AUGUSTIN e ARANHA, 2006). 
Figura 7 - Imagens do interior da Voçoroca, Setas Vermelhas indicam as cicatrizes de movimentos de massa, Setas Pretas indicam depósitos que ocorreram próximo à cabeira.

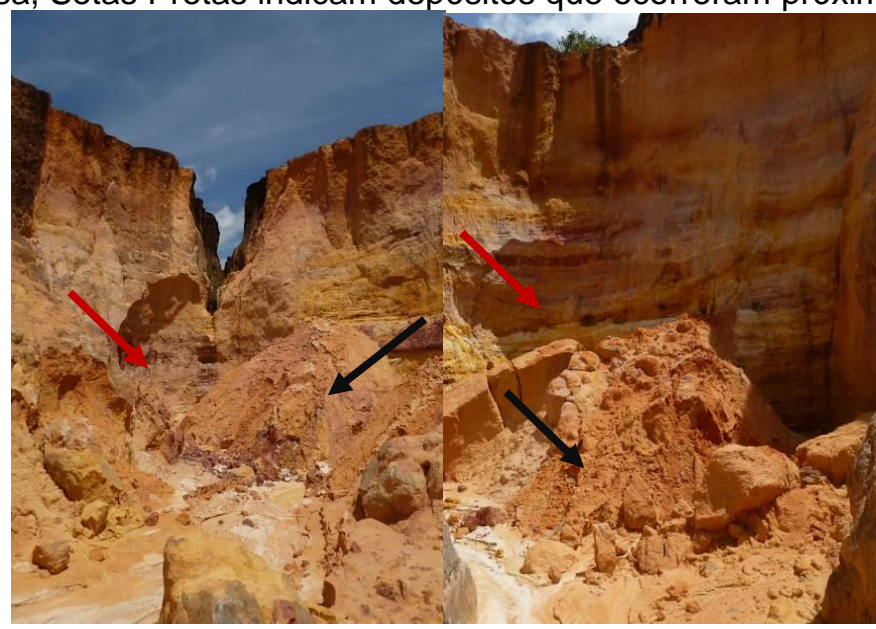

Fonte - Armando Brito da Frota Filho, 2017.

Outra feição de retrabalhamento bastante expressiva são as alcovas de regressão, as quais se desenvolvem na parte inferior das paredes da voçoroca. Essas feições tendem a desestabilizar as camadas de solo acima desta, resultando em desmoronamento por perda de sustentação, sendo importantes na identificação dos materiais e mecanismos envolvidos na expansão das voçorocas (OLIVEIRA, 1995).

$\mathrm{Na}$ Figura 8 podem ser observadas duas alcovas de regressão na parede esquerda, próxima à cabeceira da voçoroca. Trata-se, portanto, de um processo de retrabalhamento que é intrinsecamente ligado ao crescimento da incisão, tendo em vista que à medida que a alcova de regressão cresce, maior será a instabilidade da parede e deflagrando o movimento de massa, ampliando as dimensões da voçoroca (FIGURA 8).

Figura 8 - A: Alcova de regressão e sedimentos de um movimento de massa recente. B: Alcovas de regressão encontrados no interior da incisão, cabeceira da voçoroca.

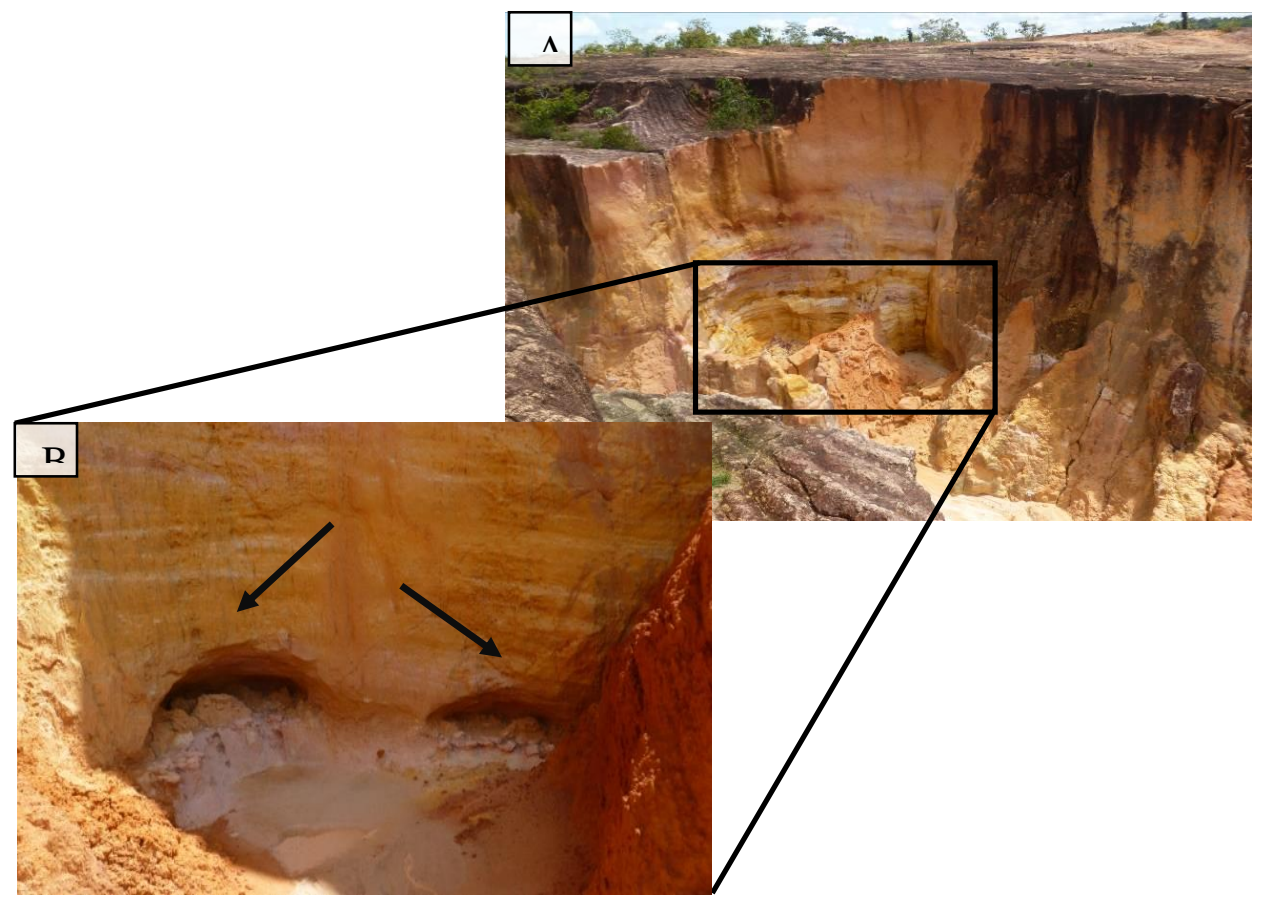

Org. Armando Brito da Frota Filho e Nádia Rafaela Pereira de Abreu, 2017. 
Thornes (1984) assinala que as voçorocas são dinamicamente similares a pequenos canais fluviais, sendo caracterizadas como parte do sistema hidrográfico da bacia quando conectada ao sistema de drenagem. Pode apresentar fluxos efêmeros d'água e contribuir de forma direta com sedimentos das vertentes para a rede de drenagem.

A voçoroca é classificada pelo modelo de Oliveira (1989) como conectada à rede de drenagem, e essa ligação resulta no carreamento do material erodido da incisão, diretamente para a rede hidrográfica, ocasionando assoreamento do canal e soterramento da vegetação adjacente. (Figura 8 e 9) através dos sedimentos destacados desta incisão, tal dinâmica pode ser identificada por meio de imagens de satélite.

Figura 8 - Voçoroca (seta vermelha) em área de sítio arquelógico, bairro Nova Cidade. Ao fundo, (área de deposição dos sedimentos oriundos da voçoroca, formando um leque de deposição (seta amarela).

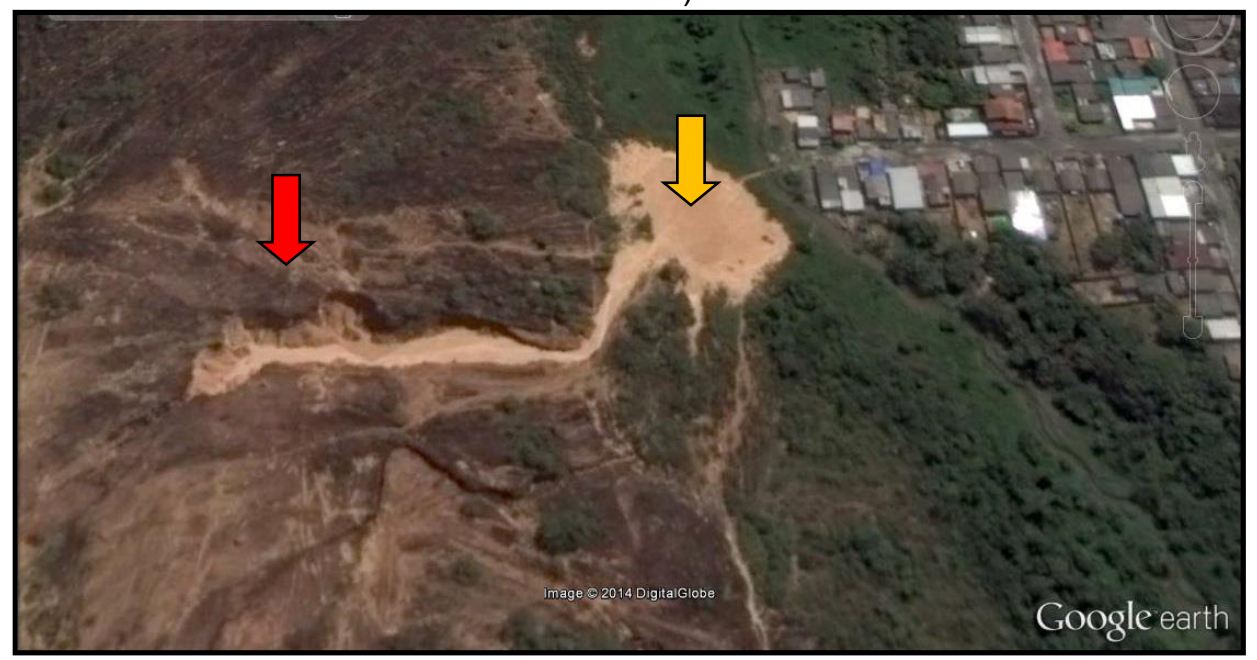

Org.: Armando Brito da Frota Filho e Nádia Rafaela Pereira de Abreu, 2017. Fonte - Imagem Google Earth, 2014.

Figura 9 - Área de deposição de sedimentos ao fundo da voçoroca, em seta em amarelo indica direção do fluxo.

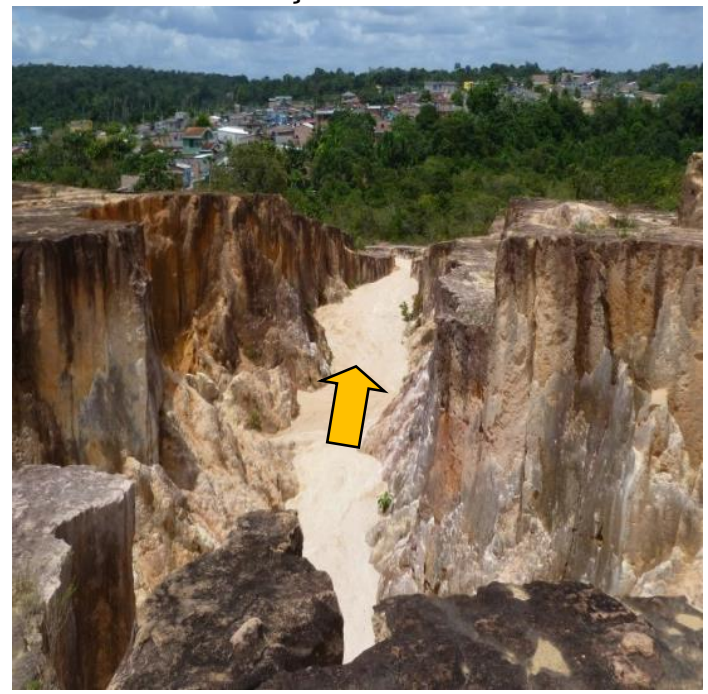

Org: Armando Brito da Frota Filho, 2017.

Em 10 anos a voçoroca teve um aumento substancial em seu tamanho (comprimento), de aproximadamente 27 m de comprimento em 2005 para cerca de 110 m em 2014 (Figura 10). 
Acredita-se que por haver feições de retrabalhamento no interior da voçoroca, essa está condicionada a continuar sua expansão. Caso uma contenção não seja feita na voçoroca, a incisão poderá chegar até a via de acesso.

Figura 10 - A - voçoroca em 2005; B - voçoroca em 2014. Setas pretas indicam a localização da voçoroca.

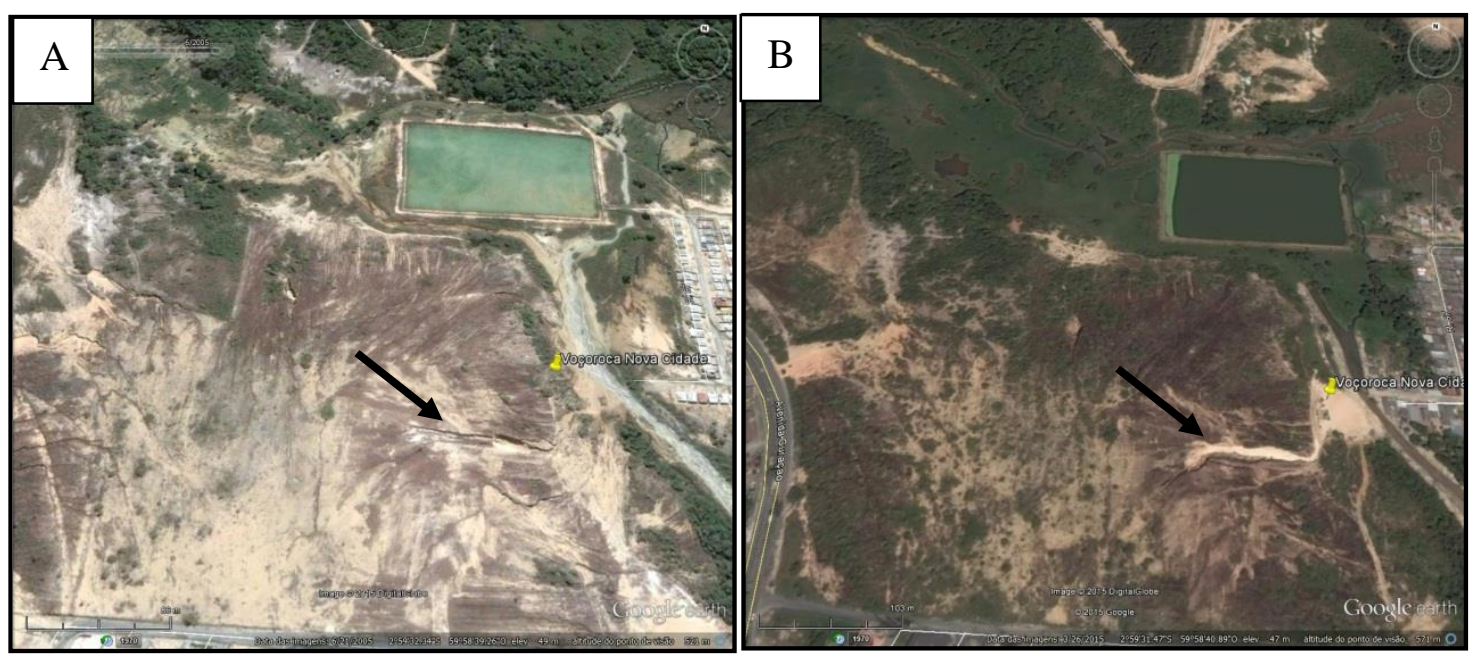

Org.: Armando Brito da Frota Filho e Nádia Rafaela Pereira de Abreu, 2015 Fonte - Imagem Google Earth.de 2005 e 2014

\section{CONSIDERAÇÕES FINAIS}

Verificou-se que a área do presente trabalho está em processo de reconfiguração, primeiramente pela ocupação ocorrida a partir de 2005 e pelo desenvolvimento da voçoroca no local. As feições de retrabalhamento, tais como marmitas e alcovas de regressão, possibilitaram identificar o sentido de expansão da voçoroca, uma vez que elas contribuem nesse processo.

Verificou-se também que do período da primeira imagem em 2005 em que surge incisão, até o ano de 2014, seu comprimento aumentou em cerca de $83 \mathrm{~m}$ de comprimento, ou seja, de aproximadamente $27 \mathrm{~m}$ naquele primeiro ano, para cerca de $110 \mathrm{~m}$ no último ano monitorado pelas imagens. Corrobora para esse crescimento, a ausência de vegetação associada à compactação do solo, favorecendo a formação de fluxos superficiais concentrados.

Em face da existência das feições de retrabalhamento em suas paredes, a voçoroca continua em expansão tanto à montante, como nas bordas laterais. Até o último monitoramento, a área erodida da incisão já havia alcançado aproximadamente $17.600 \mathrm{~m}^{2}$. Vale destacar que essa área ocupada pela incisão e mais a área de seu entorno, estão inutilizados, em virtude da possibilidade de se tornar área de risco. O mesmo pode ser dito para a área a jusante da incisão, a qual recebe os sedimentos carreados e teve seu córrego assoreado, além dos impactos na vegetação, a qual foi em boa parte soterrada. Um prognóstico acerca disso é o impacto desses sedimentos às habitações mais a jusante.

A fim de evitar maiores impactos e mitigar os já existentes, uma possível abordagem versa sobre a revegetação da área de contribuição à montante e no entorno das bordas da incisão, a suavização das paredes por meio de patamares e a inserção de barreiras de contenção no interior da incisão, tenderiam com o tempo a diminuir a velocidade de expansão e até mesmo a barrar seu crescimento. Tais medidas já foram aplicadas em outras voçorocas na cidade de Manaus, com resultados positivos. 


\section{REFERÊNCIAS}

ABREU, N.R.P. ;VIEIRA, A. F. G. ; FROTA FILHO, A. B. . A Relação do Controle Estrutural com Processos de Voçorocamentos Em Manaus (AM): Uma Análise Preliminar. In: IX Simpósio Nacional de Geomorfologia, 2012, Rio de Janeiro, RJ. Anais... Rio de Janeiro, 2012 p.1-5

AUGUSTIN, C.H.R.R. ; ARANHA, P.R.A. Voçorocas em Gouveia, MG: Características e Processos Associados. Geonomos, Belo Horizonte, v. 14, p. 75-86.

BOTELHO, R. G. M.; DA SILVA, A. S. Bacia hidrográfica e qualidade ambiental. In: VITTE, A. C.; GUERRA, A. J. T. Reflexões sobre a geografia física no Brasil. Rio de Janeiro: Bertrand Brasil, 2004. p.153-192

COSTA, R.C.R.da; NATALI FILHO, T. e OLIVEIRA, A.A.B.de. Geomorfologia. In: Projeto RADAMBRASIL. Folha SA 20. Manaus. Rio de Janeiro: DNPM, 1978. p. 165-244

D'ÁVILA JUNIOR, J.C.M. Análise dos padrões pluviométricos da cidade de Manaus-AM no período de 1986 a 2015. 2016. 60 f. Relatório de Pesquisa (Iniciação Científica). Universidade Federal do Amazonas. Manaus: PROPESP, 2016.

FROTA FILHO, A.B.; VIEIRA, A.F.G.; ANDRADE, J.M.B.; ABREU, N.R.P. Análise geral do risco a movimentos de massa e voçorocamentos nas microbacias Colônia Antônio Aleixo e Boa Vista (Manaus AM). In: IX Simpósio Nacional de Geomorfologia, 2012, Rio de Janeiro, RJ. Anais... Rio de Janeiro, 2012. p.1-4

GUERRA, A,J,T. GUERRA, A,T. Novo dicionário geológico- geomorfológico. 8 ed. Rio de Janeiro: Betrand Brasil, 2010. 652p.

LEAL, P. C. Caracterização e interpretações genéticas de alguns solos da região de ManausAM. 1996. 109 f. Dissertação (Mestrado). Ciências do Solo. Universidade Federal Rural de Pernambuco, Recife-PE, 1996.

VIEIRA, A. F. G. Desenvolvimento e distribuição de voçorocas em Manaus (am): principais fatores controladores e Impactos urbano-ambientais. 2008. 310 f. Tese (Doutorado em Geografia). Universidade Federal de Santa Catarina, Florianópolis, 2008.

OLIVEIRA, M. A. T. Erosion Disconformities and Gully Morphology: A Threedimensional Approach. In: Catena, Germany, v.16, p.413-423, 1989. https://doi.org/10.1016/0341-8162(89)90024-6

OLIVEIRA, M.A.T. Processos erosivos e preservação de áreas de risco de erosão por voçorocas. In: GUERRA, A.J.T.; SILVA, A.S.; BOTELHO, R.G.M. (Orgs.). Erosão e Conservação dos Solos: Conceitos, temas e aplicações. Rio de Janeiro: Edgard Biucher, 2007. p.57-99

RODRIGUES, C.; MOROZ-CACCIA GOUVEIA, I. C. A importância do fator antrópico na redefinição de processos geomorfológicos e riscos associados em áreas urbanizadas do meio tropical úmido. Exemplos na Grande São Paulo. In: GUERRA, A.J.T.; JORGE, M.C.O. (Orgs.). Processos Erosivos e Recuperação de Áreas Degradadas. São Paulo: Oficina de Textos, 2013. p. 01-192.

SANTANA, G.F. Análise dos padrões térmicos da cidade de Manaus-AM, no período de 1986 a 2015. 2017. 173 f. Relatório de Pesquisa (Iniciação à Pesquisa). Universidade Federal do Amazonas. Manaus: PROPESP, 2017.

SELBY, M. J. Hillslope Materials \& Processes. New York: Oxford University Press, 1990. 264p.

SILVA, A. M. Rainfall erosivity map for Brazil. In: Catena, Amesterdã, v.57, p.251-259, 2004. https://doi.org/10.1016/i.catena.2003.11.006

SILVA, C. L.; Análise da tectônica cenozoica da região de Manaus e adjacências. Tese. (Doutorado em Geologia). 2005. 309 f. UNESP, Rio Claro - SP, 2005.

SUGUIO, K. Geologia Sedimentar. São Paulo: Editora Blucher, 2003.p. 25-29.

THORNES, J.B. Procesos erosivos de las corrientes de agua y sus controles espaciales y temporales: un punto de vista teórico. In: KIRBBY, M.J., MORGAN, R.P.C.(Orgs.). Erosion de suelos. México - D.F.: Ed. LUMASA, 1984. p.165-226 
TUCCI, C. E. M.; CLARKE, R. T. Impacto das mudanças da cobertura vegetal no escoamento: Revisão. In: Revista Brasileira de Recursos Hídricos, v.2, n.1, p.135-152, 1997. https://doi.org/10.21168/rbrh.v2n1.p135-152

VALENTIN, C. POESEN, J. LI, YONG. Gully erosion: Impacts, factors and control. In: Catena, Amesterdã, v. 63, p.132-153, 2005. https://doi.org/10.1016/i.catena.2005.06.001

VIEIRA, A.F.G.; ALBUQUERQUE, A. R. Cadastramento de voçorocas e análise de risco erosivo em estradas: BR-174. In: V Simpósio Nacional de Geomorfologia, 2004, Santa Maria - RS. Anais... Santa Maria: Editora da UFSM, 2004. p.50-65.

VIEIRA, A. F. G. Desenvolvimento e distribuição de voçorocas em Manaus (am): principais fatores controladores e Impactos urbano-ambientais. 2008. 310 f. Tese (Doutorado em Geografia). Universidade Federal de Santa Catarina, Florianópolis, 2008.

WOO, M.; GUOXIANG, F.; DICENZO, P. The role of vegetation in the retardation of rill erosion. In: Catena, Amsterdã, v. 29, p.145-159, 1997. https://doi.org/10.1016/S0341-8162(96)00052-5

Recebido em: 17/04/2019

Aceito para publicação em: 03/03/2020 